JPDN ISSN 2579-6461 (Online) ISSN 2460-6324 (Print)

Jurnal Pendidikan Dasar Nusantara

Volume 6| Nomor $1 \mid$ Juli 2020|

DOI: https://doi.org/10.29407/jpdn.v6i1.14412

\title{
PENGARUH MODEL PEMBELAJARAN SAVI BERBANTUAN MEDIA KAPINDO UNTUK MENINGKATKAN BERPIKIR KRITIS SISWA PADA TEMA 6 KELAS IV
}

\author{
Lina Rosidah $^{1}$, Savitri Wanabuliandari², dan Sekar Dwi Ardianti ${ }^{3}$ \\ linarosidah2@gmail.com ${ }^{1,}$ savitri.wanabuliandari@umk.ac.id ${ }^{2}$, \\ sekar.dwi.ardianti@umk.ac.id ${ }^{3}$ \\ PGSD, FKIP, Universitas Muria Kudus ${ }^{1}$ \\ Pendidikan Matematika, FKIP, Universitas Muria Kudus ${ }^{2}$ \\ PGSD, FKIP, Universitas Muria Kudus ${ }^{3}$ \\ No Handphone: +6285799412778
}

\begin{abstract}
Abstrak: Tujuan penelitian ini adalah menganalisis perbedaan berpikir kritis siswa aspek pengetahuan sebelum dan sesudah diterapkan model pembelajaran SAVI berbantuan media KAPINDO, menganalisis peningkatan berpikir kritis siswa aspek pengetahuan dan keterampilan dengan model pembelajaran SAVI berbantuan media KAPINDO. Jenis penelitian ini adalah pre-experimental design dengan one-group pretest-postest design. Penelitian ini dilaksanakan di kelas IV SD Negeri 1 Pelemkerep Jepara. Variabel bebas dalam penelitian ini adalah model pembelajaran SAVI berbantuan media KAPINDO, sedangkan variabel terikatnya adalah berpikir kritis siswa. Teknik analisis data yang digunakan yaitu uji z dan uji n-gain. Hasil penelitian mendapatkan bahwa (1) berpikir kritis siswa aspek pengetahuan setelah diterapkan model pembelajaran SAVI berbantuan media KAPINDO lebih baik dibandingakan sebelum diberi perlakuan. Hal ini terlihat dari nilai $Z_{\text {hitung }}-4,16<-Z_{\text {tabel }}-1,96$. (2) penggunaan model pembelajaran SAVI berbantuan media KAPINDO dapat meningkatkan berpikir kritis siswa aspek pengetahuan dan keterampilan. Hal tersebut dapat dilihat dari nilai gain aspek pengetahuan dengan nilai 0,3673 kategori sedang dan nilai gain aspek keterampilan dengan nilai 0,5186 kategori sedang.
\end{abstract}

Kata kunci: Berpikir Kritis, SAVI, KAPINDO.

\section{THE INFLUENCE OF SAVI LEARNING MODEL AS AID BY KAPINDO MEDIA TO IMPROVE STUDENT CRITICAL THINKING IN THEME 6 CLASS IV}

\begin{abstract}
The purpose of this study was to analyze differences in students 'critical thinking aspects of knowledge before and after KAPINDO's media-assisted SAVI learning model was applied, analyze the students' critical thinking and knowledge enhancement aspects with KAPINDO's media-assisted SAVI learning model. This type of research is a pre-experimental design with one-group pretest-posttest design. This
\end{abstract}


Lina, Savitri, Sekar. Pengaruh Model Pembelajaran SAVI

research was conducted in class IV SD Negeri 1 Pelemkerep Jepara. The independent variable in this study is SAVI learning model assisted by KAPINDO media, while the dependent variable is students' critical thinking. Data analysis techniques used are the $\mathrm{z}$ test and the n-gain test. The results showed that (1) students' critical thinking aspects of knowledge after applying the SAVI learning model assisted by KAPINDO media was better than before being given treatment. This can be seen from the value of Zhitung 4.16 <-Ztable -1.96. (2) the use of SAVI learning models assisted by KAPINDO media can improve students' critical thinking aspects of knowledge and skills. This can be seen from the gain value of knowledge aspects with a value of 0.3673 in the medium category and the value of the skill aspect gain with a value of 0.5186 in the medium category.

Keywords: Critical Thinking, SAVI, KAPINDO.

\section{PENDAHULUAN}

Pendidikan merupakan hal yang penting bagi kelangsungan hidup manusia dalam pembentukan dan pengembangan kualitas sumber daya manusia dalam menghadapi kemajuan zaman. Tujuan pendidikan nasional tercantum dalam UndangUndang RI No. 20 tahun 2003 tentang Sistem Pendidikan Nasional Bab 1 Pasal 1 Ayat 1 menyatakan bahwa: "Pendidikan adalah usaha sadar dan terencana untuk mewujudkan suasana belajar dan proses belajar agar peserta didik secara aktif mengembangkan potensi dirinya untuk memiliki kekuatan spiritual keagamaan, pengendalian diri, kepribadian, kecerdasan, akhlak mulia, serta keterampilan yang diperlukan dirinya, masyarakat, bangsa, dan negara”. Era globalisasi seperti sekarang ini, menuntut setiap negara untuk meningkatkan kualitas pendidikannya. Salah satu upaya pemerintah melakukan pemerataan dan peningkatan pendidikan agar tujuan Pendidikan Nasional dapat tercapai, yaitu melalui pembelajaran di sekolah dasar.

Pembelajaran di sekolah dasar pada saat ini sudah menerapkan Kurikulum 2013. Di sekolah dasar baik kelas rendah maupun tinggi menerapkan kurikulum 2013 dengan pembelajaran berbasis tematik. Pembelajaran tematik merupakan pembelajaran terpadu yang menggunakan tema untuk mengaitkan beberapa muatan mata pelajaran sehingga dapat memberikan pengalaman bermakna kepada peserta didik (Ardianti, Ulya \& Ismaya, 2018: 19). Pembelajaran tematik memiliki satu tema yang aktual dekat dengan dunia siswa dan ada dalam kehidupan sehari-hari. Tema tersebut menjadi satu pemersatu materi yang beragam dari beberapa muatan. Tetapi antar materi harus 
Lina, Savitri, Sekar. Pengaruh Model Pembelajaran SAVI

memiliki keterkaitan, agar pada pembelajaran tidak terjadi penyimpangan yang menimbulkan permasalahan belajar.

Untuk mengatasi berbagai permasalahan belajar diperlukan pembelajaran inovatif dan menyenangkan yang sesuai dengan Kurikulum 2013. Alternatif pembelajaran inovatif adalah dengan menggunakan model pembelajaran. Model pembelajaran adalah suatu pola interaksi antara siswa dan guru di dalam kelas yang terdiri dari strategi, pendekatan, metode, dan teknik pembelajaran yang diterapkan dalam pelaksanaan kegiatan pembelajaran di kelas (Lestari \& Yudhanegara, 2018: 37). Salah satu model pembelajaran inovatif Kurikulum 2013 adalah model pembelajaran SAVI (Somatic, Auditory Visualization Intellectualy). Menurut Lestari \& Yudhanegara (2018: 57) SAVI merupakan model pembelajaran yang melibatkan gerakan, seperti gerakan fisik anggota badan tertentu, berbicara, mendengarkan, melihat, mengamati, dan menggunakan kemampuan intelektual untuk berpikir, menggambarkan, menghubungkan, dan membuat kesimpulan. Istilah SAVI adalah kependendekan dari Somatic (belajar dengan bergerak dan berbuat), Auditory (belajar dengan berbicara dan mendengar), Visualization (belajar dengan mengamati dan menggambarkan), Intellectualy (belajar dengan memecahkan masalah dan berpikir). Model pembelajaran SAVI memiliki empat langkah, yaitu tahap persiapan, tahap penyampaian, tahap pelatihan, dan tahap penampilan hasil. Pembelajaran SAVI menekankan bahwa belajar haruslah memanfaatkan semua alat indra yang dimiliki siswa (Shoimin, 2017: 177). Hal ini bertujuan untuk membangkitkan kecerdasan terpadu siswa secara penuh melalui penggabungan gerak fisik dengan aktivitas intelektual. Hal ini sejalan dengan penelitian Fitriyani, Suwatra \& Kusmariyatni (2015: 11) yang menyatakan bahwa model pembelajaran SAVI berpengaruh terhadap kemampuan berpikir kritis IPA siswa di kelas V SD gugus II Sahadewa Kecamatan Negara. Selain itu Yohani, Rakhmat \& Mulyana (2014: 120) menyatakan bahwa terdapat pengaruh dari pendekatan SAVI terhadap hasil belajar pada pembelajaran subtema macam-macam energi di kelas IV SD Negeri Pasirmalang dan SD Negeri Bunisari UPTD Pendidikan Kecamatan Cigalontang Tasikmalaya.

Selain menggunakan model pembelajaran digunakan bantuan media dalam pembelajaran. Media pembelajaran dapat dimanfaatkan untuk menjembatani obyek pembelajaran yang tidak dapat dilihat dengan mata biasa (Ardianti, Christijanti \& 


\section{Lina, Savitri, Sekar. Pengaruh Model Pembelajaran SAVI}

Dewi, 2012: 75). Dengan menggunakan bantuan media pembelajaran diharapkan siswa menjadi lebih tertarik dan aktif dalam pembelajaran yang berlangsung. Peneliti akan membuat sebuah media yang diberi nama media KAPINDO "Kantong Pintar Doraemon". KAPINDO adalah sebuah media dalam bentuk doraemon berukuran besar yang terdapat beberapa kantong, didalam kantong tersebut berisi gambar pengetahuan dalam bentuk puzzle dan soal yang dibuat menarik. Dengan menggunakan media KAPINDO diharapkan memudahkan siswa dalam belajar. Hal ini sejalan dengan penelitian Faridha, Yulianto \& Laksono (2017: 425) yang menyatakan penggunaan media Kantong Ajaib Doraemon digunakan dalam pembelajaran karena media ini sangat dikenali oleh anak-anak terutama anak usia sekolah dasar.

Model pembelajaran SAVI berbantuan media KAPINDO memberikan kesempatan kepada siswa untuk berinteraksi antar anggota kelompok. Berinteraksi dengan anggota kelompok baik di tahap penyampaian atau pun di tahap pelatihan akan membantu siswa meningkatkan kualitas berpikirnya dalam memecahkan masalah dan memperluas pengetahuan. Berinteraksi dengan anggota kelompok akan melatih siswa bersikap terbuka terhadap informasi, pernyataan, dan pengalaman orang lain sehingga akan membantu meningkatkan berpikir kritis.

Berpikir kritis adalah sebuah proses terorganisasi yang memungkinkan siswa mengevaluasi bukti, asumsi, logika, dan bahasa yang mendasari pernyataan orang lain (Johnson, 2014: 185). Sedangkan menurut Ennis (2015: 1) menyatakan "Critical Thingking is reasonable reflective thingking focused on deciding what to believe or do" artinya Berpikir kritis adalah pemikiran reflektif yang masuk akal yang difokuskan pada memutuskan apa yang harus dipercaya. Berpikir kritis akan mengembangkan pengetahuan dan keterampilan siswa dengan mencari informasi sebanyak-banyaknya untuk dianalisis, mensisntesis, dan mengevaluasi pengetahuan tersebut sehingga dapat membuat generalisasi. Tujuannya untuk meningkatkan berpikir kritis siswa dalam menghadapi kehidupan yang akan datang.

Kenyataannya berpikir kritis siswa di sekolah dasar masih sangat rendah. Hal ini berdasarkan hasil studi pendahuluan saya pada tanggal 3-5 Oktober 2019 di kelas IV SD 1 Pelemkerep Kecamatan Mayong Kabupaten Jepara. Diperoleh informasi bahwa pembelajaran IPA dan Bahasa Indonesia yang berlangsung belum mampu mengajak siswa terlibat aktif dalam pembelajaran. Selain itu, interaksi siswa dengan 
Lina, Savitri, Sekar. Pengaruh Model Pembelajaran SAVI

lingkungan, objek nyata dan hal yang konkrit belum terlihat. Pembelajaran yang berlangsung masih terfokus pada kegiatan siswa yang hanya menghafal materi, sehingga membuat siswa malas untuk berpikir. Seharusnya siswa aktif menumbuhkembangkan kemampuan dan keterampilan berpikirnya, salah satunya adalah berpikir kritis. Rendahnya berpikir kritis diperkuat dengan hasil tes subjektif IPA dan Bahasa Indonesia siswa kelas IV SD 1 Pelemkerep. Berdasarkan hasil tes tersebut diketahui bahwa rata-rata nilai berpikir kritis IPA dan Bahasa Indonesia SD 1 Pelemkerep adalah 52,6. Berdasarkan data tersebut, diketahui bahwa rata-rata berpikir kritis siswa berada pada kriteria perlu bimbingan, nilai tersebut berada pada tingkat rendah.

Rendahnya berpikir kritis siswa SD 1 Pelemkerep diperkuat dengan observasi pada proses pembelajaran dan wawancara pada guru dan siswa kelas IV. Berdasarkan kegiatan tersebut, ada beberapa faktor yang diyakini menjadi penyebab rendahnya berpikir kritis siswa yaitu: 1) Guru masih menggunakan model konvensional dan metode ceramah masih mendominasi guru dalam mengajar; 2) Guru yang mendominasi dengan metode ceramah tidak didukung dengan media pembelajaran yang menarik siswa. Padahal guru bisa memanfaatkan benda-benda disekitar siswa sebagai media pembelajaran. Tujuan dari media adalah untuk membantu siswa menerima pembelajaran yang diberikan oleh guru, agar apa yang disampaikan guru dapat bersifat nyata; 3) Guru masih belum terbiasa memberikan evaluasi yang memungkinkan siswa untuk berpikir kritis.

Berdasarkan permasalahan yang peneliti temukan maka perlu adanya perbaikan untuk mengatasi permasalahan tersebut. Peneliti menerapkan model pembelajaran SAVI berbantuan media KAPINDO. Model pembelajaran SAVI berbantuan media KAPINDO dapat memberikan ruang bagi peserta didik untuk mengembangkan berpikir kritisnya dengan memanfaatkan Somatic, Aditory, Visualization, Intellectualy dalam proses pembelajaran.

Tujuan dalam penelitian ini adalah (1) Menganalisis perbedaan berpikir kritis aspek pengetahuan sebelum dan sesudah diterapkan model pembelajaran SAVI berbantuan media KAPINDO. (2) Menganalisis peningkatan berpikir kritis aspek pengetahuan dengan model pembelajaran SAVI berbantuan media KAPINDO. (3) 
Lina, Savitri, Sekar. Pengaruh Model Pembelajaran SAVI

Menganalisis peningkatan berpikir kritis aspek keterampilan dengan model pembelajaran SAVI berbantuan media KAPINDO.

\section{METODE}

Tempat pelaksanaan penelitian ini adalah di kelas IV SD Negeri 1 Pelemkerep, Kecamatan Mayong Kabupaten Jepara. Adapun waktu penelitian ini yaitu pada bulan Oktober 2019 sampai bulan Januari 2020. Populasi dalam penelitian ini adalah siswa kelas IV di SD 1 Pelemkerep dengan jumlah siswa 39 orang. Teknik pengambilan sampel yang digunakan dalam penelitian ini adalah Sampling Jenuh. Karena semua siswa kelas IV SD 1 Pelemkerep dijadikan sebagai sampel. Rancangan penelitian ini adalah pre-experimental design dengan one-group pretest-postest design. Dapat dilihat pada gambar berikut.

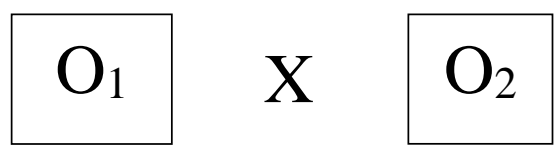

\section{Gambar 1 Desain penelitian one-group pretest-postest design}

$$
\begin{aligned}
& \text { Keterangan : } \\
& \mathrm{O}_{1}=\text { Pretest } \\
& \mathrm{X}=\text { Penerepan model SAVI berbantuan media KAPIDO } \\
& \mathrm{O}_{2}=\text { Posttest }
\end{aligned}
$$

Gambar 1 menjelaskan bahwa, penelitian ini dilakukan dengan membandingkan hasil tes berpikir kritis $\mathrm{O}_{1}$ dan $\mathrm{O}_{2} . \mathrm{O}_{1}$ adalah nilai tes berpikir kritis sebelum menggunakan model pembelajaran SAVI berbantuan KAPINDO, sedangkan $\mathrm{O}_{2}$ adalah nilai tes berpikir kritis setelah menggunakan model pembelajaran SAVI berbantuan KAPINDO. Data yang dikumpulkan dalam penelitian ini adalah hasil observasi, wawancara, tes dan dokumentasi. Instrumen yang digunakan dalam penelitian ini adalah Pedoman observasi berisikan daftar berbagai jenis kegiatan yang muncul dan akan diamati. Pedoman observasi digunakan untuk mengukur proses pembelajaran dan aktivitas siswa. Selanjutnya yaitu Lembar wawanacara berisi daftar beberapa pertanyaan yang akan ditanyakan pada guru dan siswa kelas IV SD 1 Pelemkerep. Yang terakhir adalah lembar tes subjektif. Jumlah soal 10 uraian, yang terdiri dari 5 
Lina, Savitri, Sekar. Pengaruh Model Pembelajaran SAVI

soal muatan IPA dan 5 soal muatan Bahasa Indonesia. Tes tersebut memuat 5 indikator berpikir kritis yang telah ditetapkan oleh peneliti.

Teknik analisis data yang digunakan yaitu uji z dan uji n-gain. Uji z digunakan untuk mengetahui perbedaan berpikir kritis aspek pengetahuan sebelum dan sesudah diterapkan model SAVI berbantuan media KAPINDO. Berikut rumus dari uji z dua sampel dependen.

$$
\mathrm{Z}_{\text {hitung }}=\frac{\mu_{D-\sqrt{n}}}{\sigma_{D}}
$$

$$
\begin{aligned}
& \text { Keterangan : } \\
& \mathrm{D}=\text { Perbedaan pasangan data } \\
& \mu_{D}=\text { Rata-rata dari perbedaan pasangan data } \\
& \sigma_{D}=\text { Simpangan baku/standar deviasi dari perbedaan pasangan data }
\end{aligned}
$$

Sedangkan uji n-gain digunakan untuk mengetahui besar peningkatan berpikir kritis aspek pengetahuan dan keterampilan. Berikut rumus dari n-gain.

$$
\text { N. Gain }=\frac{\text { Skor Postes }- \text { Skor Pretes }}{\text { Skor Maksimum Ideal }- \text { Skor Pretes }}
$$

\section{HASIL}

Hasil penelitian ini meliputi : (1) perbedaan berpikir kritis aspek pengetahuan; (2) peningkatan berpikir kritis aspek pengetahuan; (3) peningkatan berpikir kritis aspek keterampilan.

\section{1) Perbedaan Berpikir Kritis Aspek Pengetahuan}

Analisis perbedaan berpikir kritis aspek pengetahuan menggunakan uji z untuk dua sampel dependen. Hasil analisis dapat dilihat pada tabel berikut :

\section{Tabel 1 Hasil Analisis Uji Z untuk Dua Sampel Dependen}

\begin{tabular}{|c|c|c|}
\hline $\mathbf{Z}_{\text {hitung }}$ & $-\mathbf{Z}_{\text {tabel }}$ & Keterangan \\
\hline$-4,16$ & $-1,96$ & $\mathrm{H}_{\mathrm{o}}$ ditolak \\
\hline
\end{tabular}

Nilai $Z_{\text {hitung }}<-Z_{\text {tabel }}$ maka $\mathrm{H}_{\mathrm{o}}$ ditolak, artinya pada taraf kepercayaan $95 \%$ dapat disimpulkan terdapat perbedaan berpikir kritis aspek pengetahuan sebelum dan sesudah diterapkan model pembelajaran SAVI berbantuan media KAPINDO. 
Lina, Savitri, Sekar. Pengaruh Model Pembelajaran SAVI

\section{2) Peningkatan Berpikir Kritis Aspek Pengetahuan}

Adapun hasil pengujian N-Gain dapat dilihat pada tabel berikut:

Tabel 2 Analisis Peningkatan Berpikir Kritis Aspek Pengetahuan Klasikal

\begin{tabular}{|c|c|}
\hline N-Gain & Kriteria N-Gain \\
\hline 0,3673 & Sedang \\
\hline
\end{tabular}

Berdasarkan Tabel 2 menunjukkan bahwa nilai $\mathrm{N}$-Gain kelas IV SD 1

Pelemkerep secara klasikal menunjukkan peningkatan berpikir kritis aspek pengetahuan dengan nilai 0,3673. Hal ini berarti peningkatan berada pada kriteria sedang. Sedangkan peningkatan secara individu siswa kelas IV SD 1 Pelemkerep dapat dilihat pada tabel berikut :

Tabel 3 Analisis Peningkatan Berpikir Kritis Aspek Pengetahuan Individu

\begin{tabular}{|l|c|c|}
\hline \multicolumn{1}{|c|}{ Kriteria } & Jumlah Siswa & Presentase \\
\hline Tinggi & 0 & $0 \%$ \\
\hline Sedang & 31 & $79,5 \%$ \\
\hline Rendah & 8 & $20,5 \%$ \\
\hline
\end{tabular}

Berdasarkan Tabel 3 dapat diketahui bahwa hasil peningkatan berpikir kritis aspek pengetahuan dengan tingkat paling tinggi sebesar 0\%, sedang sebesar 79,5\% dengan jumlah 31 siswa, dan rendah sebesar 20,5\% dengan jumlah 8 siswa.

Sehingga dapat ditarik kesimpulan bahwa terdapat peningkatan berpikir kritis aspek pengetahuan siswa SD 1 Pelemkerep setelah diterapkan model pembelajaran SAVI berbantuan media KAPINDO dengan kriteria sedang.

\section{3) Peningkatan Berpikir Kritis Aspek Keterampilan}

Adapun hasil pengujian N-Gain dapat dilihat pada tabel berikut:

Tabel 4 Analisis Peningkatan Berpikir Kritis Aspek Keterampilan Klasikal

\begin{tabular}{|c|c|}
\hline N-Gain & Interpretasi N-Gain \\
\hline 0,5186 & Sedang \\
\hline
\end{tabular}

Berdasarkan Tabel 4 menunjukkan bahwa nilai $\mathrm{N}$-Gain kelas IV SD 1 Pelemkerep secara klasikal menunjukkan peningkatan berpikir kritis aspek keterampilan dengan nilai 0,5186. Hal ini berarti peningkatan berada pada kriteria sedang. Sedangakan peningkatan secara individu siswa kelas IV SD 1 Pelemkerep dapat dilihat pada tabel berikut : 
Lina, Savitri, Sekar. Pengaruh Model Pembelajaran SAVI

Tabel 5 Analisis Peningkatan Berpikir Kritis Aspek Keterampilan Individu

\begin{tabular}{|l|c|c|}
\hline \multicolumn{1}{|c|}{ Kriteria } & Jumlah Siswa & Presentase \\
\hline Tinggi & 5 & $12,8 \%$ \\
\hline Sedang & 31 & $79,5 \%$ \\
\hline Rendah & 3 & $7,7 \%$ \\
\hline
\end{tabular}

Berdasarkan Tabel 5 dapat diketahui bahwa hasil peningkatan berpikir kritis aspek keterampilan dengan tingkat paling tinggi sebesar 12,8\% dengan jumlah 5 siswa, sedang sebesar 79,5\% dengan jumlah 31 siswa, dan rendah sebesar 7,7\% dengan jumlah 3 siswa. Sehingga dapat ditarik kesimpulan bahwa terdapat peningkatan berpikir kritis aspek keterampilan siswa SD 1 Pelemkerep setelah diterapkan model pembelajaran SAVI berbantuan media KAPINDO dengan kriteria sedang.

\section{PEMBAHASAN}

\section{1) Perbedaan Berpikir Kritis Aspek Pengetahuan}

Pengujian data yang pertama yaitu uji perbedaan berpikir kritis aspek pengetahuan sebelum dan sesudah menerapkan model pembelajaran SAVI berbantuan media KAPINDO. Uji ini menggunakan uji z untuk dua sampel dependen berbantuan aplikasi Microsoft Excel 2016. Pembelajaran menggunakan model pembelajaran SAVI berbantuan media KAPINDO diawali dengan mengerjakan soal pretest untuk mengetahui kemampuan awal dan diakhiri dengan soal posttest untuk mengetahui kemampuan siswa setelah diberi perlakuan. Data nilai pretest dan posttest kemudian diuji untuk mengetahui perbedaan nilai berpikir kritis aspek pengetahuan sebelum dan sesudah diberi perlakuan. Berdasarkan hasil perhitungan menunjukkan bahwa nilai

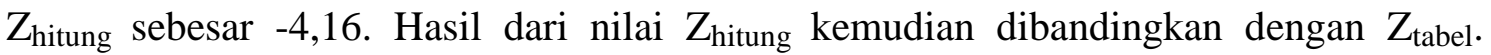
Diperoleh $Z_{\text {hitung }}<-Z_{\text {tabel }}$ yakni $-4,16<-1,96$, maka $\mathrm{H}_{\mathrm{o}}$ ditolak dan $\mathrm{H}_{\mathrm{a}}$ diterima. Sehingga dapat disimpulkan bahwa terdapat perbedaan berpikir kritis aspek pengetahuan sebelum dan sesudah diterapkan model pembelajaran SAVI berbantuan media KAPINDO.

Penerapan model pembelajaran SAVI berbantuan media KAPINDO memberikan perbedaan terhadap nilai pretest dan posttest. Tingkat berpikir kritis aspek pengetahuan setelah diberi perlakuan lebih tinggi dibandingkan sebelum diberi 
Lina, Savitri, Sekar. Pengaruh Model Pembelajaran SAVI

perlakuan. Rata-rata nilai siswa SD 1 Pelemkerep setelah diberi perlakuan mencapai $66,73 \%$ lebih baik sebelum diberi perlakuan yang hanya mencapai 48,08\%. Berdasarkan rata-rata tersebut diketahui bahwa setelah diberi perlakuan, rata-rata nilai siswa SD 1 Pelemkerep meningkat sebesar 18,65\%. Sehingga berpikir kritis aspek pengetahuan menggunakan model pembelajaran SAVI berbantuan media KAPINDO lebih baik dibandingkan sebelumnya.

Hal ini sejalan dengan penelitian Sutarna (2018: 123) yang menyatakan bahwa terdapat perbedaan yang signifikan antara hasil belajar siswa sebelum dan sesudah menerapkan model pembelajaran SAVI. Fitriyani, dkk. (2015: 8) juga menyatakan bahwa data hasil penelitian kelompok siswa yang mengikuti pembelajaran dengan menerapkan model pembelajaran SAVI memiliki rata-rata skor kemampuan berpikir kritis IPA yang lebih tinggi dibandingkan dengan kelompok siswa yang mengikuti model pembelajaran konvensional. Hasil penelitian lain yang juga mendukung penelitian ini adalah hasil penelitian Wati, dkk. (2014: 8) menyatakan bahwa siswa yang dibelajarkan menggunakan model pembelajaran SAVI berbantuan media bahan ajar hasil belajarnya lebih baik dari pada siswa yang dibelajarkan melalui pembelajaran konvensional pada materi persiapan kemerdekaan Indonesia dan peristiwa proklamasi kemerdekaan.

Perbedaan berpikir kritis aspek pengetahuan siswa SD 1 Pelemkerep sebelum dan sesudah diterapkan model dan media disebabkan karena perbedaan perlakuan pada langkah-langkah pembelajaran dan proses penyampaian materi. Model pembelajaran SAVI berbantuan media KAPINDO lebih menekankan pada pengembangan berpikir kritis siswa, sedangkan model pembelajaran konvensional menekankan pada hafalan.

\section{2) Analisis Peningkatan Berpikir Kritis Aspek Pengetahuan}

Pengujian data yang kedua yaitu uji peningkatan berpikir kritis aspek pengetahuan setelah menerapkan model pembelajaran SAVI berbantuan media KAPINDO. Uji ini menggunakan aplikasi SPSS 22 yaitu dengan uji N-Gain. Besarnya peningkatan sebelum dan sesudah diberi perlakuan dihitung menggunakan N-Gain, yaitu selisih nilai posttest dengan nilai pretest dibagi selisih nilai maksmimum ideal dengan nilai pretest. Berdasarkan nilai pretest dan posttest berpikir kritis aspek pengetahuan diperoleh nilai gain secara klasikal sebesar 0,3673 hal ini menunjukkan 
Lina, Savitri, Sekar. Pengaruh Model Pembelajaran SAVI

peningkatan berpikir kritis aspek pengetahuan dengan kriteria sedang. Sedangkan secara individu dari 39 siswa kelas IV SD 1 Pelemkerep tidak ada siswa yang berada pada kriteria tinggi dengan presentase sebesar 0\%, untuk kriteria sedang sebanyak 31 siswa dengan presentase 79,5\%, dan 8 siswa berada pada kriteria rendah sebesar 20,5\%. Sehingga dapat ditarik kesimpulan bahwa terdapat peningkatan berpikir kritis aspek pengetahuan siswa SD 1 Pelemkerep setelah diterapkan model pembelajaran SAVI berbantuan media KAPINDO dengan kategori sedang .

Hal ini sejalan dengan penelitian Kusumawati (2018: 223) yang menyatakan bahwa model pembelajaran SAVI dapat meningkatkan hasil belajar IPA pada siswa kelas V SDN Mangkujayan. Farhana, dkk. (2016: 318) juga menyatakan bahwa kemampuan berpikir kritis siswa kelas eksperimen (diberi perlakuan) mengalami peningkatan yang tinggi dan lebih baik dibandingkan dengan peningkatan kemampuan berpikir kritis siswa kelas kontrol (tidak diberi perlakuan). Hasil penelitian lain yang juga mendukung penelitian ini adalah hasil penelitian Azizah, dkk. (2016: 499) menyatakan bahwa hasil belajar siswa setelah diterapkan SAVI mengalami peningkatan dan tujuan pembelajaran telah tercapai dengan baik, pada siklus III peningkatan yang terjadi telah mencapai target yang diinginkan dengan jumlah siswa yang tuntas 22 orang siswa dan yang belum tuntas 3 orang siswa.

Peningkatan terjadi disebabkan karena proses pembelajaran yang diperoleh siswa berbeda, sebelumnya menggunakan model konvensional dan belum dimodifikasi dengan model pembelajaran yang inovatif. Model pembelajaran SAVI berbantuan media KAPINDO mengajak keterlibatan siswa untuk lebih aktif dalam proses pembelajaran, selain itu tumbuhnya keberanian siswa untuk mengutarakan pendapat. Siswa juga dapat belajar memecahkan masalah sendiri dan bekerjasama antara siswa dalam berkelompok. Peningkatan presentase yang terjadi menunjukkan bahwa penerapan model pembelajaran SAVI berbantuan media KAPINDO yang telah dilakukan dengan tujuan untuk meningkatkan berpikir kritis aspek pengetahuan mendapat respon yang baik dan berpengaruh bagi siswa kelas IV SD 1 Pelemkerep.

\section{3) Analisis Peningkatan Berpikir Kritis Aspek Keterampilan}

Hasil pengamatan keterampilan praktik siswa SD 1 Pelemkerep setelah menerapkan model pembelajaran SAVI berbantuan media KAPINDO mengalami peningkatan. Adapun penilaian keterampilan praktik terdiri dari 5 aspek, diantaranya: 
Lina, Savitri, Sekar. Pengaruh Model Pembelajaran SAVI

(1) menyusun puzzle; (2) presentasi; (3) melisankan puisi; (4) menyajikan hasil pengamatan; (5) melaporkan hasil pengamatan. Aspek yang diamati menggunakan nilai skor 0-3 yang kemudian dilakukan uji peningkatan berpikir kritis aspek keterampilan. Uji ini menggunakan aplikasi SPSS 22 yaitu dengan uji N-Gain. Diperoleh nilai NGain secara klasikal sebesar 0,5186 hal ini menunjukkan peningkatan berpikir kritis aspek keterampilan dengan kriteria sedang. Sedangkan secara individu dari 39 siswa kelas IV SD 1 Pelemkerep 5 siswa berada pada kriteria tinggi dengan presentase sebesar $12,8 \%$, untuk kriteria sedang sebanyak 31 siswa dengan presentase 79,5\%, dan 3 siswa berada pada kriteria rendah sebesar 7,7\%. Sehingga dapat ditarik kesimpulan bahwa terdapat peningkatan berpikir kritis aspek keterampilan siswa SD 1 Pelemkerep setelah diterapkan model pembelajaran SAVI berbantuan media KAPINDO dengan kategori sedang.

Hal ini sejalan dengan penelitian Iskandar, dkk. (2016: 45) yang menyatakan that by applying the model in study SAVI social science with social problems in the local environment can enhance students' critical thinking skills. The result can be seen from the percentage of the overall level of mastery learning increased from $52.2 \%$ in the first cycle, $78.3 \%$ in the second cycle and $100 \%$ in the third cycle (bahwa dengan menerapkan model SAVI dalam studi ilmu sosial dengan masalah sosial di lingkungan lokal dapat meningkatkan keterampilan berpikir kritis siswa. Hasilnya bisa dilihat dari persentase dari keseluruhan tingkat penguasaan pembelajaran meningkat dari $52,2 \%$ pada siklus pertama, 78,3\% pada siklus kedua dan 100\% di siklus ketiga). Azizah, dkk. (2016: 499) juga menyatakan bahwa aktivitas siswa pada setiap siklus tindakan mengalami peningkatan setiap aspek yang diamati, walaupun terdapat beberapa siswa yang belum tuntas namun secara keseluruhan aktivitas siswa meningkat dan mencapai target yang diinginkan. Menurut (Kusumawati \& Gunansyah (2013: 7) peningkatan hasil aktivitas siswa karena terbiasa dengan kegiatan pembelajaran yang menggunakan model pembelajaran SAVI. Siswa menjadi lebih aktif serta berani dalam mengungkapkan pendapatnya, siswa mulai dapat bekerjasama dalam kelompok heterogen.

Menumbuhkembangkan keterampilan berpikir kritis mulai jenjang SD memang dimungkinkan, namun dengan pertimbangan tahap perkembangannya. Siswa SD berada pada tahap perkembangan intelektual operasional konkret. Pada tahap ini anak mampu 
Lina, Savitri, Sekar. Pengaruh Model Pembelajaran SAVI

berpikir logis dengan kehadiran benda-benda konkret, bukan hanya dengan konsepkonsep yang dihafalkan (Ardiyanti \& Winarti, 2013: 28). Pernyataan ini sesuai dengan model pembelajaran SAVI yang mengarahkan siswa untuk tidak mudah menerima begitu saja pengetahuan hanya karena selama ini memang begitu caranya, tetapi melalui sesuatu yang bersifat nyata.

Diuraikan untuk menjawab hasil/data penelitian secara komprehensif sesuai dengan tujuan. Pembahasan bertujuan untuk memaknai hasil penelitian sesuai dengan teori dan hasil-hasil penelitian sebelumnya.

\section{SIMPULAN}

Berdasarkan penelitian yang telah dilakukan, hasil dan pembahasan penelitian pengaruh model pembelajaran Somatic Auditory Visualization Intellectualy berbantuan media KAPINDO untuk meningkatkan berpikir kritis siswa pada Tema 6 Cita-citaku kelas IV SD 1 Pelemkerep, dipaparkan sebagai berikut :

1. Terdapat perbedaan berpikir kritis aspek pengetahuan siswa SD 1 Pelemkerep sebelum dan sesudah diterapkan model pembelajaran SAVI berbantuan media KAPINDO dengan nilai $Z_{\text {hitung }}-4,16<-Z_{\text {tabel }}-1,96$.

2. Terjadi peningkatan berpikir kritis aspek pengetahuan siswa SD 1 Pelemkerep dengan model pembelajaran SAVI berbantuan media KAPINDO dengan nilai NGain 0,3673 pada kategori sedang.

3. Terjadi peningkatan berpikir kritis aspek keterampilan siswa SD 1 Pelemkerep dengan model pembelajaran SAVI berbantuan media KAPINDO dengan nilai NGain 0,5186 pada kategori sedang.

\section{UCAPAN TERIMA KASIH}

Terimakasih kepada seluruh pihak yang telah membantu menyelesaikan penelitian ini. Peneliti juga mengucapkan terimakasih kepada Universitas Muria Kudus, Dosen pembimbing, Kepala Sekolah SD Negeri 1 Pelemkerep, Guru kelas IV SD Negeri 1 Pelemkerep, Siswa kelas IV SD Negeri 1 Pelemkerep, serta teman-temanku yang selalu memberikan semangat dan dukungan. 
Lina, Savitri, Sekar. Pengaruh Model Pembelajaran SAVI

\section{DAFTAR RUJUKAN}

Ardianti, Sekar Dwi., Christijanti, Wulan \& Dewi, Pramesti. 2012. Peran Media Animasi dengan Metode Pembelajaran Time Token Terhadap Aktivitas dan Hasil Belajar. Unnes Journal of Biology Education, 1 (1), 74-78.

Ardianti, Sekar Dwi., Ulya, Himmatul \& Ismaya, Erik Aditia. 2018. Pakem dalam Kurikulum 2013. Kudus: Badan Penerbit Universitas Muria Kudus.

Ardianti, Sekar Dwi., Wanabuliandari, Savitri \& Rahardjo, Susilo. 2019. The Implementation Of E-JAS Science Edutainment To Improve Elementary School Student's Conceptual Understanding. Unnes Science Education Journal, 8 (1), 16.

Ardiyanti, Farida \& Winarti. 2013. Pengaruh Model Pembelajaran Berbasis Fenomena untuk Meningkatkan Keterampilan Berpikir Kritis Siswa Sekolah Dasar. ISSN, 9 (2), 27-33.

Azizah, Nur., Sujana, Atep \& Isrok'atun. 2016. Penerapan Pendekatan Somatis Auditori Visual Intelektual pada Materi Sumber Energi Bunyi untuk Meningkatkan Hasil Belajar Siswa. Jurnal Pena Ilmiah, 1 (1), 491-500.

Ennis, Robert H. 2015. The Nature of Critical Thinking Outlines of General Critical Thinking Dispositions and Abilities. University of Illinois, 1-11.

Fakhriyah, Fina., Wanabuliandari, Savitri \& Ardianti, Sekar Dwi. 2016. Pendampingan Pemanfaatan Sampah Plastik dan Kertas untuk Media Pembelajaran Inovatif bagi Guru di SDN 5 Bae Kudus. Jurnal Pengabdian Pada Masyarakat, 1 (1), 48-55.

Farhana., Oyon Haki Pranata \& Hamdu, Ghullam. 2016. Penerapan Strategi Pemecahan Masalah dalam Peningkatan Kemampuan Berpikir Kritis Siswa pada Pembagian Pecahan. PGSD Universitas Pendidikan Indonesia Tasikmalaya, 303-321.

Faridha, Dyan., Yulianto, Bambang \& Laksono, Kisyani. 2017. Penerapan Media Kantong Ajaib Doraemon dengan Model Omeake untuk Meningkatkan Kemampuan Membuat Kalimat Tanya Siswa Kelas V SDN Sukoanyar 01 Malang. Jurnal Kajian Pendidikan dan Hasil Penelitian, 3 (2), 424-428.

Fitriyani., Suwatra \& Kusmariyatni. 2015. Pengaruh Model SAVI Terhadap Kemampuan Berpikir Kritis Siswa dalam Mata Pelajaran IPA Kelas V SD. EJournal PGSD Universitas Pendidikan Ganesha, 3 (1), 1-12.

Iskandar, Dadang., Hamdani, Acep Roni \& Suhartini, Teti. 2016. Implemetation Of Model SAVI (Somatic, Audiotory, Visualization, Intellectual) To Increase Critical Thinking Ability In Class IV Of Social Science Learning On Social Issues In The Local Environment. Journal of Education Teaching and Learning, 1 (1), 45-50.

Johnson, Elaine B. 2014. Contextual Teaching and Learning. Bandung : Kaifa.

Kusumawati, Naniek. 2018. Peningkatan Hasil Belajar Siswa Kelas V dengan Model Pembelajaran SAVI pada Mata Pelajaran IPA di SDN Mangkujayan 1 Kabupaten Ponorogo. Jurnal Pendidikan Dasar Nusantara, 3 (2), 217-224. 
Lina, Savitri, Sekar. Pengaruh Model Pembelajaran SAVI

Kusumawati, Sri Wahyuni \& Gunansyah, Ganes. 2013. Penerapan Model Pembelajaran SAVI untuk Meningkatkan Katerampilan Pemecahan Masalah di Sekolah Dasar. JPGSD, 1 (2), 1-10.

Lestari, Eka Karunia \& Yudhanegara, Mokhammad Ridwan. 2018. Penelitian Pendidikan Matematika. Bandung : PT Refika Aditama.

Rohmah, Sri Ainur., Fakhriyah, Fina \& Ardianti, Sekar Dwi. 2019. Peningkatan Pemahaman Konsep Melalui Model CTL Berbantuan Media Kotak Lingkungan Hewan Pada Tema 6 Kelas IV. Jurnal Prakarsa Paedagogia, 2 (2), 185-191.

Shoimin, Aris. 2017. 68 Model Pembelajaran Inovatif dalam Kurikulum 2013. Yogyakarta : Ar-Ruzz Media.

Undang-Undang Republik Nomor 20 Tahun 2003. 2003. Sistem Pendidikan Nasional. Jakarta : Dewan Perwakilan Rakyat Republik Indonesia dan Presiden republik Indonesia.

Sutarna, Nana. 2018. Pengaruh Model Pembelajaran SAVI Terhadap Hasil Belajar Siswa Kelas IV Sekolah Dasar. JPPD, 5 (2), 119-126.

Wanabuliandari, Savitri., Fakhriyah, Fina \& Ardianti, Sekar Dwi. 2020. Pengabdian PTK untuk Guru di SD 1 Tumpang Krasak dengan Teknik Participant Active Learning. Jurnal Pengabdian Pada Mayarakat, 2 (2), 209-214.

Wanabuliandari, Savitri \& Ristiyani. 2019. Program Hypnomathematics melalui Katakata Positif untuk Guru SD 2 Bae Kudus. Jurnal Pengabdian Pada Mayarakat, 4 (3), 249-254.

Wati, Ni Putu Dita Wisna., Darsana, I Wayan \& Suardika, I Wayan Rinda. 2014. Pengaruh Model Pembelajaran Somatic Auditory Visual Intelectual (SAVI) Berbantuan Bahan Ajar Terhadap Hasil Belajar IPS Siswa Kelas V SD Gugus Raden Ajeng Kartini. Jurnal Mimbar PGSD Universitas Pendidikan Ganesha, 2 (1), 1-10.

Yohani, Desi Fatwani., Rakhmat, Cece \& Mulyana, Edi Hendri. 2014. Pengaruh Pendekatan Pembelajaran SAVI Terhadap Hasil Belajar pada Pembelajaran Tematik di Sekolah Dasar. PGSD Universitas Pendidikan Indonesia Kampus Tasikmalaya, 113-120. 